\title{
A Critique of the UK NICE Guidance for the Detection and Management of Individuals with Chronic Kidney Disease
}

\author{
Arif Khwaja David Throssell \\ Sheffield Kidney Institute, Northern General Hospital, Sheffield, UK
}

\section{Key Words}

Chronic kidney disease $\cdot$ End-stage renal disease .

UK NICE guidelines

\begin{abstract}
The increasing global prevalence of chronic kidney disease (CKD) and end-stage renal disease (ESRD) has significant public health and economic implications. The recently published UK National Institute for Health and Clinical Excellence (NICE) clinical guidelines for the early identification and management of CKD provide a framework of disease management for both primary and secondary care with the stated aim of reducing the progression of CKD and the associated risk of cardiovascular death. Identification of at-risk individuals with proteinuria and inhibition of the renin-angiotensin system are the cornerstones of this strategy. However, the vast majority of patients with CKD will not develop ESRD and it is far from clear whether the NICE recommendations will reduce either ESRD or cardiovascular death associated with CKD.

Copyright $\odot 2009$ S. Karger AG, Basel
\end{abstract}

\section{Introduction}

The widespread adoption of the Kidney Disease Outcomes Quality Initiative (K/DOQI) classification of chronic kidney disease (CKD) [1] coupled with the use of

\section{KARGER}

Fax +4161306 1234 E-Mail karger@karger.ch www.karger.com (c) 2009 S. Karger AG, Basel

$1660-2110 / 09 / 1133-0207 \$ 26.00 / 0$

Accessible online at:

www.karger.com/nec estimated glomerular filtration rate (eGFR) to assess excretory renal function has resulted in up to $10 \%$ of the population being labeled as having chronic kidney disease [2]. Furthermore there has been a staggering rise in the number of patients requiring renal replacement (RRT) - in the UK alone the prevalent number of patients on RRT between 2000 and 2006 increased by 35\% [3] and similar trends have been seen globally. Of course the increasing prevalence of patients on RRT may reflect improved access to RRT and better survival on RRT rather than a true increase in the incidence or prevalence of antecedent non-end-stage renal disease (non-ESRD). Indeed, there is no clear-cut relationship between CKD prevalence in the community and the need for RRT. Furthermore many have argued that the use of the $\mathrm{K} / \mathrm{DOQI}$ classification to estimate CKD prevalence is inherently flawed as much of the data are based on single creatinine measurements and inappropriate use of microalbuminuria data to define CKD [4].

Notwithstanding the concerns about the validity of the epidemiological data, many perceive that the failure to detect CKD early and the late referral of patients with advanced CKD are key factors that underlie this inexorable rise in RRT. The public health and economic ramifications of this 'epidemic' are profound and have underpinned numerous international efforts to enable early identification and appropriate management of CKD.

In the UK the National Institute for Health and Clinical Excellence (NICE) has produced clinical guidance 
Table 1. Summary of NICE guidance

a Stages of chronic kidney disease

\begin{tabular}{lll}
\hline Stage & eGFR $\left(\mathrm{ml} / \mathrm{min} / 1.73 \mathrm{~m}^{2}\right)$ & Comment \\
\hline 1 & $\geq 90$ & - Stages 1 and 2 must have other evidence of kidney damage for more than $3 \mathrm{months}$ \\
2 & $60-89$ & - For stages $3-5 \mathrm{GFR}<60 \mathrm{ml} / \mathrm{min} / 1.73 \mathrm{~m}^{2}$ for greater than $3 \mathrm{months} \mathrm{regardless} \mathrm{of} \mathrm{other}$ \\
$3 \mathrm{~A}$ & $45-59$ & evidence of kidney damage \\
$3 \mathrm{~B}$ & $30-44$ & - The suffix ' $\mathrm{p}$ ' used to denote proteinuria if ACR $\geq 30 \mathrm{mg} / \mathrm{mmol} \mathrm{or} \mathrm{PCR} \geq 50 \mathrm{mg} / \mathrm{mmol}$ \\
4 & $15-29$ & \\
5 & $<15$ & \\
\hline
\end{tabular}

b Key management recommendations

\begin{tabular}{ll}
\hline Control blood pressure & - Target systolic $120-139 \mathrm{~mm} \mathrm{Hg}$, diastolic $<90 \mathrm{~mm} \mathrm{Hg}$ \\
& - Diabetes and CKD and/or ACR $\geq 70 \mathrm{mg} / \mathrm{mmol}$ target systolic $120-129 \mathrm{~mm} \mathrm{Hg}$ and \\
& diastolic $<80 \mathrm{~mm} \mathrm{Hg}$ \\
\hline Use of angiotensin-converting & - Diabetics with ACR $>2.5 \mathrm{mg} / \mathrm{mmol}(\mathrm{men})$ and $>3.5 \mathrm{mg} / \mathrm{mmol}(\mathrm{women})$ \\
enzyme inhibitors or & - CKD and ACR $>70 \mathrm{mg} / \mathrm{mmol}$ \\
angiotensin receptor blockers & - CKD, hypertension and ACR $>30 \mathrm{mg} / \mathrm{mmol}$ \\
\hline Reduce cardiovascular risk & - Lipid-lowering and anti-platelet agents \\
\hline Referral criteria to secondary care & - CKD 4 and 5 \\
& - Proteinuria with ACR $\geq 70 \mathrm{mg} / \mathrm{mmol}$ and PCR $\geq 100 \mathrm{mg} / \mathrm{mmol}$ \\
& - Hematuria and proteinuria $(\mathrm{ACR} \geq 30 \mathrm{mg} / \mathrm{mmol})$ \\
& - Progressive CKD; eGFR declines by $>5 \mathrm{ml} / \mathrm{min} / 1.73 \mathrm{~m}{ }^{2}$ over 1 year or \\
& 10 ml $/$ min $/ 1.73 \mathrm{~m}{ }^{2}$ over 10 years \\
& - Poorly controlled hypertension \\
& - Rare or genetic kidney disease \\
& - Suspected renal artery stenosis \\
&
\end{tabular}

aimed at optimizing the care of patients with CKD [5]. In particular, the guidelines focus on identifying patients at risk of progressive CKD by ensuring that kidney function is measured in high-risk groups [e.g. patients with diabetes, hypertension and cardiovascular disease (CVD)] and by quantifying proteinuria in patients with CKD. Furthermore specific guidance is provided on blood pressure control, the use of angiotensin-converting enzyme inhibitors (ACEIs)/angiotensin receptor blockers (ARBs) and the indications for, and timing of, referral to secondary care. The key priorities for implementation are summarized in table 1 and comparison with other national nephrology associations are included in table 2 .

The commendable aims of the guidance are to identify and, if possible, stabilize early CKD in the hope that this will prevent or delay its progression, and reduce associated complications, thereby benefiting both patients and the wider health economy. The purpose of this review is to appraise key aspects of the NICE guidance and focus on the evidence base underpinning the guidance.

\section{Classification of CKD and Cardiovascular Disease}

The use of eGFR to classify CKD initially proposed by K/DOQI has been widely adopted internationally. However, there has been significant concern that the current classification system inappropriately labels large numbers of mostly elderly and female subjects as having CKD 3 without other objective evidence of kidney disease [6]. Furthermore others have argued that the diagnosis of CKD 3 is of little clinical relevance as the risk of CKD 3 progressing to end-stage renal failure is relatively small [7]. For example, a 5-year longitudinal study of over 27,000 patients in a healthcare maintenance organization found that the rate of RRT for patients with CKD 3 was only $1.3 \%[8]$.

Some of these concerns are addressed by the NICE proposal to subdivide CKD 3 into stage 3A (eGFR between $45-59 \mathrm{ml} / \mathrm{min} / 1.73 \mathrm{~m}^{2}$ ) and stage $3 \mathrm{~B}$ (eGFR between $30-44 \mathrm{ml} / \mathrm{min} / 1.73 \mathrm{~m}^{2}$ ). This subdivision has been driven by large-scale observational data demonstrating 
that cardiovascular and all-cause mortality increase significantly when GFR declines [9-11]. For example, the largest of these studies showed a hazard ratio for cardiovascular events to be 2.0 (95\% CI 1.9-2.1) and for death from any cause to be 1.8 (95\% CI 1.7-1.9) when the eGFR was $<45 \mathrm{ml} / \mathrm{min} / 1.73 \mathrm{~m}^{2}$ [9].

Whilst CKD 3B may identify individuals at increased risk of cardiovascular death, it is important to remember that CVD itself increases the risk of subsequent development of CKD [12]. Furthermore it is difficult to extrapolate the results of interventional cardiovascular trials to patients with CKD given the widespread exclusion of patients with significant CKD from such studies [13]. Whilst a prospective observational cohort study of 1,940 consecutive patients with peripheral vascular disease suggested that chronic statin and ACEI use was associated with lower renal progression [14] yet such interventions have not been conclusively shown to improve cardiovascular or renal endpoints in CKD. Indeed, there are few interventional studies to support the use of any primary intervention, beyond blood pressure control, to reduce cardiovascular death in patients with CKD. For example, NICE acknowledged the results of a recent meta-analysis involving over 30,000 patients that demonstrated there was no evidence to support the role of statins either in reducing all-cause mortality or in primary prevention of cardiovascular events in patients with CKD [15].

Intuitively the subdivision of CKD 3 seems sensible in that it will focus the resources of primary care onto those patients with significantly abnormal kidney function and address the concerns of many that CKD 3 represents far too broad a range of kidney function to have any meaningful clinical utility. However, whilst CKD 3B is associated with significant CVD, there is no evidence that identification of these individuals per se, will trigger interventions that improve cardiovascular outcomes.

\section{Detection of Proteinuria and Inhibition of Renin-Angiotensin Axis}

Proteinuria has long been recognized as a powerful predictor of progression of CKD, and therefore the decision by NICE to incorporate proteinuria (by use of the suffix ' $p$ ') into CKD staging is a pragmatic and clinically useful refinement of the classification system. However, there are a number of concerns about both the testing procedure recommended by NICE and the suggested definition of 'significant proteinuria'.
Table 2. Comparison of international guidelines for the management of hypertension in CKD

\begin{tabular}{|c|c|}
\hline Organization & Recommendations \\
\hline $\begin{array}{l}\text { K/DOQI } \\
\text { guidelines } \\
{[26]}\end{array}$ & $\begin{array}{l}\text { Diabetic CKD } \\
\text { ACEI/ARB preferentially } \\
\text { Other agents to reduce CVD risk and reach BP } \\
\text { target: diuretic preferred, then BB or CCB } \\
\text { Non-diabetic CKD with urine PCR }>200 \mathrm{mg} / \mathrm{g} \\
\text { As for diabetic CKD } \\
\text { Non-diabetic CKD with urine PCR }<200 \mathrm{mg} / \mathrm{g} \\
\text { None preferred } \\
\text { Other agents to reduce CVD risk and reach BP } \\
\text { target: diuretic preferred, then ACEI, ARB, BB } \\
\text { or CCB } \\
\text { CKD in the transplant recipient } \\
\text { None preferred } \\
\text { Other agents to reduce CVD risk and reach BP } \\
\text { target: CCB, diuretic, BB, ACEI, ARB }\end{array}$ \\
\hline $\begin{array}{l}\text { NICE CKD } \\
\text { guidelines [5] }\end{array}$ & $\begin{array}{l}\text { Diabetic CKD } \\
\quad \text { Preferentially started with ACEI/ARB } \\
\text { CKD + hypertension + proteinuria }>0.5 \mathrm{~g} / 24 \mathrm{~h} \text { or } \\
\mathrm{ACR}>30 \mathrm{mg} / \mathrm{mmol} \\
\quad \text { Preferentially started with ACEI/ARB } \\
\text { CKD + proteinuria }(>1 \mathrm{~g} / 24 \mathrm{~h} \text { ) without hyperten- } \\
\text { sion } \\
\quad \text { Preferentially started with ACEI/ARB }\end{array}$ \\
\hline SIGN [27] & $\begin{array}{l}\text { CKD + proteinuria }>1 \mathrm{~g} / 24 \mathrm{~h} \\
\quad \text { Preferentially started with ACEI/ARB }\end{array}$ \\
\hline CARI [28] & $\begin{array}{l}\text { ACEIs and ARBs are more effective than others in } \\
\text { slowing diabetic and non-diabetic CKD }\end{array}$ \\
\hline CSN [29] & $\begin{array}{l}\text { CKD with proteinuria (proteinuria }>0.5 \mathrm{~g} / 24 \mathrm{~h} \text { or } \\
\mathrm{ACR}>30 \mathrm{mg} / \mathrm{mmol} \text { ) } \\
\text { Treatment should include an ACEI or ARB } \\
\text { Non-proteinuric CKD }(\mathrm{ACR}<30 \mathrm{mg} / \mathrm{mmol} \text { ) } \\
\text { Choice of antihypertensive agent }\end{array}$ \\
\hline
\end{tabular}

NICE = National Institute of Health and Clinical Excellence (UK); K/DOQI = Kidney Disease Outcomes Quality Initiative; SIGN = Scottish Intercollegiate Guidelines Network; CARI = Caring for Australasians with Renal Impairment; CSN = Canadian Society of Nephrology; ACEI = angiotensin-converting enzyme inhibitor; $\mathrm{ARB}=$ angiotensin receptor blocker; $\mathrm{CVD}=$ cardiovascular disease; $\mathrm{BP}=$ blood pressure; $\mathrm{BB}=\beta$-blocker; $\mathrm{CCB}=$ calcium channel blocker.

For the identification of proteinuria, NICE recommends the use of the urine albumin:creatinine ratio (ACR) rather than reagent strip testing. Whilst this makes sense for diabetics with CKD, there is no clear rationale for abandoning reagent testing for non-diabetics with CKD. Clearly ACR will be more sensitive and accurate 
than either protein:creatinine ratio (PCR) or dipstick testing in detecting low levels of proteinuria. However, the detection of microalbuminuria in non-diabetics with CKD whilst predicting adverse outcomes will not per se change the management of these patients. In our institution the cost of a single ACR is GBP 6.40 whilst a urine dipstick costs GBP 0.18. Thus given the expense of an ACR assay and the burden this places on laboratory services, there does not seem to be any justification for abandoning reagent testing to detect proteinuria in non-diabetic CKD.

In terms of quantifying proteinuria, NICE recognizes that the current dual system of using both ACR and PCR is confusing both to patients and clinicians. Whilst the guidance states that PCR can be used as an alternative to ACR for monitoring proteinuria, we believe that the use of a single assay for proteinuria will lead to less confusion in primary care. As ACR is already being used for diabetic nephropathy, there is some logic in using this assay in all cases of CKD, though primary care has only just got used to working with PCR.

NICE defined significant proteinuria as an ACR of $\geq 30 \mathrm{mg} / \mathrm{mmol}$ or a PCR of $\geq 50 \mathrm{mg} / \mathrm{mmol}$ and suggested that this should be the trigger for therapy with ACEIs or ARBs in all hypertensive CKD patients. The guidance is based on an individual patient data meta-analysis of 11 randomized controlled trials involving the use of ACEIs in non-diabetic CKD [16]. Patients were stratified by a proteinuria level of less or greater than $500 \mathrm{mg} /$ day (equivalent to an ACR of $30 \mathrm{mg} / \mathrm{mmol}$ ) and were categorized into risk quartiles for developing progressive $\mathrm{CKD}$ (defined as doubling of serum creatinine or requirement for dialysis). ACEIs conferred significant treatment benefit in all risk quartiles when proteinuria was $\geq 500 \mathrm{mg} /$ day but had no effect on outcomes with lower levels of proteinuria. There are a number of troubling aspects to this meta-analysis. Firstly, 2 of the 11 studies included have not been published. Secondly, as the authors noted 'the included studies were not themselves designed to assess the protective effects of ACEIs in patients with varying degrees of baseline proteinuria, and there is a risk for false-positive effects when multiple post hoc analyses are performed'. In fact, in only 2 of the 11 studies was the mean baseline proteinuria $<1 \mathrm{~g} /$ day, and an earlier metaanalysis of the same database by the same group revealed the lowest relative risk for CKD progression to be for patients with $<2 \mathrm{~g} /$ day [17]. The REIN-2 study, which is one of the few prospective studies specifically designed to evaluate the effect of ACEIs in non-diabetic CKD patients with differing degrees of proteinuria, found in in- dividuals with proteinuria of $<1.5 \mathrm{~g} /$ day that there was no benefit of ACEI on kidney function [18].

Does the threshold level of proteinuria really matter? Given the limitations of the above data coupled with the number of analyses showing that ACEIs are of no benefit (or possibly harmful) in CKD [19-21], we believe that NICE should have maintained the previous UK guidance [22] that ACEIs and ARBs should be offered to hypertensive, non-diabetic CKD patients with $>1 \mathrm{~g} /$ day of proteinuria. Indeed NICE recognized the 'urgent need to clarify the benefits of treatment with ACEIs/ARBs in non-diabetic CKD with lower levels of proteinuria'. Similarly we cannot see that there is a robust evidence base to support the NICE assertion that ACEIs/ARBs should be offered to all non-diabetic CKD patients with proteinuria of $>1 \mathrm{~g}$ /day regardless of whether hypertension and CVD are present. Indeed the ACE Inhibition in Progressive Renal Disease (AIPRD) meta-analysis suggested that in patients with $>1 \mathrm{~g}$ /day of proteinuria, a systolic blood pressure of $<110 \mathrm{~mm} \mathrm{Hg}$ was associated with a higher risk of CKD progression regardless of whether patients were receiving ACEIs or not [17].

\section{Impact of Age and CKD}

NICE recommends that 'at any given stage of CKD, management should not be solely influenced by age', though the guidelines suggest that clinicians should focus on those likely to require RRT within their lifetime. Whilst this avoids accusations of age discrimination, it fails to take account of the well-recognized age-related decline in GFR that occurs from the age of 20 [23] or the purported high prevalence of CKD in the elderly population. The National Health and Nutrition Examination Study demonstrated a combined CKD stages 1-3 prevalence of around $40 \%$ in those over the age of 70 years [2]. Yet the outcomes of CKD are profoundly influenced by age. An analysis of over 200,000 US veterans with CKD stages 35 followed up for more than 3 years demonstrated that for patients over the age of 65 years the risk of ESRD only exceeded the risk death when the eGFR fell to $<15 \mathrm{ml} /$ $\min / 1.73 \mathrm{~m}^{2}$ [24]. Furthermore older patients with an eGFR of $<45 \mathrm{ml} / \mathrm{min} / 1.73 \mathrm{~m}^{2}$ (i.e., those with CKD 3B under NICE guidance) were actually less likely to experience a significant decline in eGFR than younger patients. These compelling data challenge the 'age-neutral' approach endorsed by NICE in the management of CKD, suggesting that the diagnosis of CKD 3 in this age group is largely irrelevant and underlines the need for more predictive tools 
to identify those elderly individuals who are at risk of developing ESRD within their lifetime.

\section{Testing Procedure, Progression and Referral Criteria}

It is important to recognize the well-documented limitations of eGFR. The Modification of Diet in Renal Disease (MDRD) formula was derived from a relatively small sample of patients who had evidence of kidney damage. Thus many have challenged the use of eGFR alone to define CKD stage in the absence of other evidence of kidney damage [6]. Furthermore the formula underestimates GFR in patients who have a measured GFR of $>60 \mathrm{ml} /$ min whilst correction of eGFR to a standard body surface area may also give rise to errors when the individuals are very obese or very lean.

Despite these concerns, the NICE guidance provides important practical advice for primary care physicians involved in the management of CKD. Much of this guidance by its very nature is opinion-based but will provide clarity for clinicians and patients. For example, an eGFR of $<60 \mathrm{ml} / \mathrm{min} / 1.73 \mathrm{~m}^{2}$ triggers a further test within 2 weeks, whilst a minimum of 3 eGFRs over 90 days are required before defining progression. Whilst this will lead to unnecessary testing in the elderly for the reasons highlighted above, it will ensure that progressive CKD or acute kidney injury is not 'missed' in primary care. The definition of progression as a decline in eGFR of $>5 \mathrm{ml} /$ $\mathrm{min} / 1.73 \mathrm{~m}^{2}$ in 1 year or $10 \mathrm{ml} / \mathrm{min} / 1.73 \mathrm{~m}^{2}$ over 5 years is obviously arbitrary and, given the inherent variability in creatinine testing, will lead to increased referrals from primary care for people with simply fluctuating rather than deteriorating kidney function. Again this problem is exacerbated in the elderly. For example, an 80-year-old female with a creatinine of $95 \mu \mathrm{mol} / \mathrm{l}$ (eGFR $52 \mathrm{ml} /$ $\mathrm{min} / 1.73 \mathrm{~m}^{2}$ ) whose creatinine rises to $105 \mu \mathrm{mol} / \mathrm{l}$ (eGFR $47 \mathrm{ml} / \mathrm{min} / 1.73 \mathrm{~m}^{2}$ ) has by NICE criteria progressive $\mathrm{CKD}$ and therefore needs to be referred to a nephrologist. NICE calculated that a decline in eGFR of $10 \mathrm{ml} / \mathrm{min} /$ $1.73 \mathrm{~m}^{2}$ per year would carry a $95 \%$ probability of significance, and therefore we would have preferred this higher threshold for defining progression particularly amongst the elderly CKD 3 population. The definition of progression has ramifications for healthcare resources as NICE recommends that all individuals with progressive $\mathrm{CKD}$ should be offered a renal ultrasound and referral for nephrological care.

There is welcome guidance about the practicalities of renal function monitoring of ACEI/ARB therapy, which is an area of great concern within primary care. The current guidance states that ACEI/ARB therapy should continue unless there is a rise in creatinine of $30 \%$ from baseline whilst previously the UK CKD guidelines suggested a rise of $20 \%$ in creatinine as being acceptable. Primary care physicians will welcome this specific advice, but given that neither percentage figure is based on clinical data, retention of the UK CKD threshold of a creatinine rise of $20 \%$ would have been less confusing for non-nephrologists.

\section{Future Research}

NICE made welcome recommendations for areas of future research including the impact of age/gender in CKD and crucially an understanding of the mechanisms of CVD risk in CKD. However, it is not clear why NICE suggests further research into endogenous markers such as cystatin $\mathrm{C}$ that may more accurately measure kidney function in subjects in whom GFR is $>60 \mathrm{ml} / \mathrm{min} /$ $1.73 \mathrm{~m}^{2}$. Despite its many imperfections, serum creatinine is a well-established measure of kidney function, which is widely understood by clinicians - any alternative measure of excretory kidney function should only be adopted if it could be shown to improve hard clinical endpoints.

Surprisingly NICE made no comment about the role of clinical research infrastructure in the development of new therapies for progressive CKD. A bench to bedside approach has been remarkably successful in developing effective treatments in areas such as transplantation and cancer. Yet despite a plethora of potential therapies for CKD [25], there has been an abject lack of clinical trials evaluating new and existing agents. Much of this is due to a lack of interest from the pharmaceutical industry in conditions such as CKD which have 'long-distance' endpoints, and therefore makes it expensive to run clinical trials. However, given the high rate of progression even with current best practice, the development of novel therapies will be a key aspect to tackling the CKD 'epidemic'.

\section{Conclusions}

The NICE guidance for CKD is welcome and provides a useful framework for the management of patients with abnormal kidney function in primary and secondary care. Like the K/DOQI guidelines, the NICE recommendations are heavily based on expert opinion rather than hard evidence. Notwithstanding this, the NICE guide- 
lines will hopefully help to identify the relatively small number of individuals with progressive $\mathrm{CKD}$ and ensure that those at risk of CKD are locked into a chronic disease management program. The price of this will undoubtedly be more testing and inappropriate disease labeling particularly in the elderly population. The NICE refinement of CKD staging (allowing 12 categories of CKD) is a first step in changing an epidemiologically driven classification system into a meaningful clinical tool. As nephrologists we need to recognize the reality that the overwhelming majority of people with CKD will die of CVD (and not progress to ESRD) and that aside from rigorous blood pressure control, no other interventions have yet been proven to alter this outcome.

\section{References}

1 National Kidney Foundation: K/DOQI clinical practice guidelines for chronic kidney disease: evaluation, classification, and stratification. Am J Kidney Dis 2002;39(suppl 1): S1-S266.

-2 Coresh J, Astor BC, Greene T, Eknoyan G, Levey AS: Prevalence of chronic kidney disease and decreased kidney function in the adult US population: Third National Health and Nutrition Examination Survey. Am J Kidney Dis 2003;41:1-12.

3 UK Renal Registry Report 2006.

4 Glassock RJ, Winearls C: The global burden of chronic kidney disease: how valid are the estimates? Nephron Clin Pract 2008;110: c39-c47.

5 Early Identification and Management of Chronic Kidney Disease in Adults in Primary and Secondary Care. http://www.nice.org. $\mathrm{uk} / \mathrm{cg} 73$.

-6 Glassock RJ, Winearls C: Screening for CKD with eGFR: doubts and dangers. Clin J Am Soc Nephrol 2008;3:1563-1568.

7 Connolly JO, Woolfson RG: A critique of clinical guidelines for detection of individuals with chronic kidney disease. Nephron Clin Pract 2009;111:c69-c73.

$\checkmark 8$ Keith DS, Nichols GA, Gullion CM, Brown JB, Smith DH: Longitudinal follow-up and outcomes among a population with chronic kidney disease in a large managed care organization. Arch Intern Med 2004;164:659663.

-9 Go AS, Chertow GM, Fan D, McCulloch CE, Hsu CY: Chronic kidney disease and the risks of death, cardiovascular events, and hospitalization. N Engl J Med 2004;351: 1296-1305.

$\checkmark 10$ Weiner DE, Tighiouart H, Amin MG, Stark PC, MacLeod B, Griffith JL, Salem DN, Levey AS, Sarnak MJ: Chronic kidney disease as a risk factor for cardiovascular disease and all-cause mortality: a pooled analysis of community-based studies. J Am Soc Nephrol 2004;15:1307-1315.

- 11 Anavekar NS, McMurray JJ, Velazquez EJ, Solomon SD, Kober L, Rouleau JL, White HD, Nordlander R, Maggioni A, Dickstein K, Zelenkofske S, Leimberger JD, Califf RM, Pfeffer MA: Relation between renal dysfunction and cardiovascular outcomes after myocardial infarction. N Engl J Med 2004;351: 1285-1295.
12 Elsayed EF, Tighiouart H, Griffith J, Kurth T, Levey AS, Salem D, Sarnak MJ, Weiner DE: Cardiovascular disease and subsequent kidney disease. Arch Intern Med 2007;167: $1130-1136$.

13 Coca SG, Krumholz HM, Garg AX, Parikh CR: Underrepresentation of renal disease in randomized controlled trials of cardiovascular disease. JAMA 2006;296:1377-1384.

14 Feringa HH, Karagiannis SE, Chonchol M, Vidakovic R, Noordzij PG, Elhendy A, van Domburg RT, Welten G, Schouten O, Bax JJ, Berl T, Poldermans D: Lower progression rate of end-stage renal disease in patients with peripheral arterial disease using statins or angiotensin-converting enzyme inhibitors. J Am Soc Nephrol 2007;18:1872-1879.

15 Strippoli GF, Navaneethan SD, Johnson DW, Perkovic V, Pellegrini F, Nicolucci A, Craig JC: Effects of statins in patients with chronic kidney disease: meta-analysis and metaregression of randomised controlled trials. BMJ 2008;336:645-651.

16 Kent DM, Jafar TH, Hayward RA, Tighiouart $\mathrm{H}$, Landa $\mathrm{M}$, de Jong $\mathrm{P}$, de Zeeuw $\mathrm{D}$, Remuzzi G, Kamper AL, Levey AS: Progression risk, urinary protein excretion, and treatment effects of angiotensin-converting enzyme inhibitors in nondiabetic kidney disease. J Am Soc Nephrol 2007;18:19591965.

-17 Jafar TH, Stark PC, Schmid CH, Landa M, Maschio G, de Jong PE, de Zeeuw D, Shahinfar S, Toto R, Levey AS: Progression of chronic kidney disease: the role of blood pressure control, proteinuria, and angiotensin-converting enzyme inhibition: a patientlevel meta-analysis. Ann Intern Med 2003; 139:244-252.

18 Ruggenenti P, Perna A, Gherardi G, Garini G, Zoccali C, Salvadori M, Scolari F, Schena FP, Remuzzi G: Renoprotective properties of ACE-inhibition in non-diabetic nephropathies with non-nephrotic proteinuria. Lancet 1999;354:359-364.
19 Suissa S, Hutchinson T, Brophy JM, Kezouh A: ACE-inhibitor use and the long-term risk of renal failure in diabetes. Kidney Int 2006; 69:913-919.

20 Casas JP, Chua W, Loukogeorgakis S, Vallance P, Smeeth L, Hingorani AD, MacAllister RJ: Effect of inhibitors of the renin-angiotensin system and other antihypertensive drugs on renal outcomes: systematic review and meta-analysis. Lancet 2005;366:20262033

21 Onuigbo MA: Reno-prevention vs reno-protection: a critical re-appraisal of the evidence-base from the large RAAS blockade trials after ONTARGET - a call for more circumspection. QJM 2009;102:155-167.

22 Consensus Conference on Early Chronic KidneyDisease:http://www.renal.org/CKDguide/consensus.html. February 2007.

23 Epstein M: Aging and the kidney. J Am Soc Nephrol 1996;7:1106-1122.

24 O'Hare AM, Bertenthal D, Covinsky KE, Landefeld CS, Sen S, Mehta K, Steinman MA, Borzecki A, Walter LC: Mortality risk stratification in chronic kidney disease: one size for all ages? J Am Soc Nephrol 2006;17: 846-853.

25 Khwaja A, El Kossi M, Floege J, El Nahas M: The management of CKD: a look into the future. Kidney Int 2007;72:1316-1323.

26 Kidney Disease Outcomes Quality Initiative (K/DOQI): K/DOQI clinical practice guidelines on hypertension and antihypertensive agents in chronic kidney disease. Am J Kidney Dis 2004;43(suppl 1):S1-S290.

27 Scottish Intercollegiate Guidelines Network: Diagnosis and Management of Chronic Kidney Disease. http://www.sign.ac.uk/guidelines/index.html. 2008.

28 Harris D, Thomas M, Johnson D, Nicholls K, Gillin A: The CARI guidelines. Prevention of progression of kidney disease. Nephrology (Carlton) 2006;11(suppl 1):S2-S197.

29 Levin A, Hemmelgarn B, Culleton B, Tobe S, McFarlane P, Ruzicka M, Burns K, Manns B, White C, Madore F, Moist L, Klarenbach S, Barrett B, Foley R, Jindal K, Senior P, Pannu N, Shurraw S, Akbari A, Cohn A, Reslerova M, Deved V, Mendelssohn D, Nesrallah G, Kappel J, Tonelli M: Guidelines for the management of chronic kidney disease. CMAJ 2008;179:1154-1162. 


\title{
Editorial Comment
}

\author{
M. El Nahas, Sheffield
}

Drs. Khwaja and Throssell provide the reader with a thoughtful commentary on the recent (2008) UK National Institute of Health and Clinical Excellence (NICE) guidelines on CKD. They acknowledge the importance of such guidelines and the considerable amount of work taken to develop such guidance whilst being critical of some of its recommendations. They raise concern expressed by many nephrologists in the UK regarding the limited amount of evidence the guidelines' recommendations are based upon. They acknowledge the shortcomings of these guidelines in terms of their age-neutrality as age is clearly a major component of the so-called 'CKD epidemic' with the majority of those identified in communities, including the UK NEOERICA [1] survey, to suffer from CKD are over 60 years of age. Many of these do not have proteinuria, further casting doubt on the significance of moderately impaired kidney function in the elderly. In that respect, controversy and debate persist as to whether those elderly individuals suffer from CKD or from age-related physiological decline in kidney function. In that respect, it is pertinent to note that not all elderly individuals have declining kidney function and that such a decline appears to be associated with cardiovascular comorbidities as shown in a number of recent articles including that of Kshirsagar et al. [2]. Khwaja and Throssell also comment on the NICE recommendations on the initiation of ACE inhibition in patients with CKD whose proteinuria exceeds $0.5 \mathrm{~g} / 24 \mathrm{~h}$ and those whose proteinuria is over $1 \mathrm{~g} / 24 \mathrm{~h}$ even in the absence of hypertension or diabetes. Like many experienced nephrologists they raise serious doubts about such unfounded recommendations. Overall, NICE has produced comprehensive CKD guidelines that warrant the appreciation of the nephrology community. However, NICE should refrain from making recommendations that lack an evidence base but instead recommend research to inform future guidelines.

\section{References}

1 Stevens PE, O’Donoghue DJ, de Lusignan S, Van Vlymen J, Klebe B, Middleton R, Hague N, New J, Farmer CK: Chronic kidney disease management in the United Kingdom: NEOERICA project results. Kidney Int 2007;72:92-99.

-2 Kshirsagar AV, Bang H, Bomback AS, Vupputuri S, Shoham DA, Kern LM, Klemmer PJ, Mazumdar M, August PA: A simple algorithm to predict incident kidney disease. Arch Intern Med 2008;168:24662473. 